\title{
RIG-I selective Ligand RGT100
}

National Cancer Institute

\section{Source}

National Cancer Institute. RIG-I selective Ligand RGT100. NCI Thesaurus. Code C148187.

A synthetic RNA oligonucleotide and agonist of the retinoic acid-inducible gene I protein (RIG-I; DDX58), with potential antineoplastic activity. Upon intratumoral/intralesional administration, the RIG-I selective lig and RGT 100 targets and binds to the cytosolic RNA receptor RIG-I. This induces RIG-I-mediated signaling, upregulates interferon (IFN)-alfa (IFN-a) and beta (IFN-b), and induces a potent IFN-mediated innate immune response against the tumor cells. This induces the activation of natural killer (NK) cells and cytotoxic T-lymphocytes (CTL) and induces apoptosis in cancer cells. 